\title{
ASO Visual Abstract: Recurrence and Survival Rates for 1400 Early Breast Tumors Treated with Intraoperative Radiation Therapy (IORT)
}

Melvin J. Silverstein, $\mathrm{MD}^{1,2,6}$, Melinda S. Epstein, $\mathrm{PhD}^{3}$, Peter Chen, $\mathrm{MD}^{4}$, Kevin Lin, $\mathrm{MD}^{4}$, Sadia Khan, DO ${ }^{1,2}$, Lincoln Snyder, MD ${ }^{1}$, Colleen Coleman, MD $^{1}$, Lisa Guerra, MD ${ }^{1}$, Farideh Dehkordi-Vakil, $\mathrm{PhD}^{5}$, and Brian Kim, $\mathrm{MD}^{4}$

${ }^{1}$ Department of Surgery, Hoag Memorial Hospital Presbyterian, Newport Beach, CA; ${ }^{2}$ Keck School of Medicine, University of Southern California, Los Angeles, CA; ${ }^{3}$ Department of Clinical Research, Hoag Memorial Hospital Presbyterian, Newport Beach, CA; ${ }^{4}$ Department of Radiation Oncology, Hoag Memorial Hospital Presbyterian, Newport Beach, CA; ${ }^{5}$ Center for Statistical Consulting, University of California, Irvine, Irvine, CA; ${ }^{6} 3334$ E. Coast Hyw \#363, Corona Del Mar, CA 92625

Intraoperative radiotherapy (IORT) permits accurate delivery of radiation directly to the breast tumor bed during surgery. This report describes recurrence and survival data for 1400 tumors treated with x-ray IORT (https://doi.org/ 10.1245/s10434-021-11295-1).

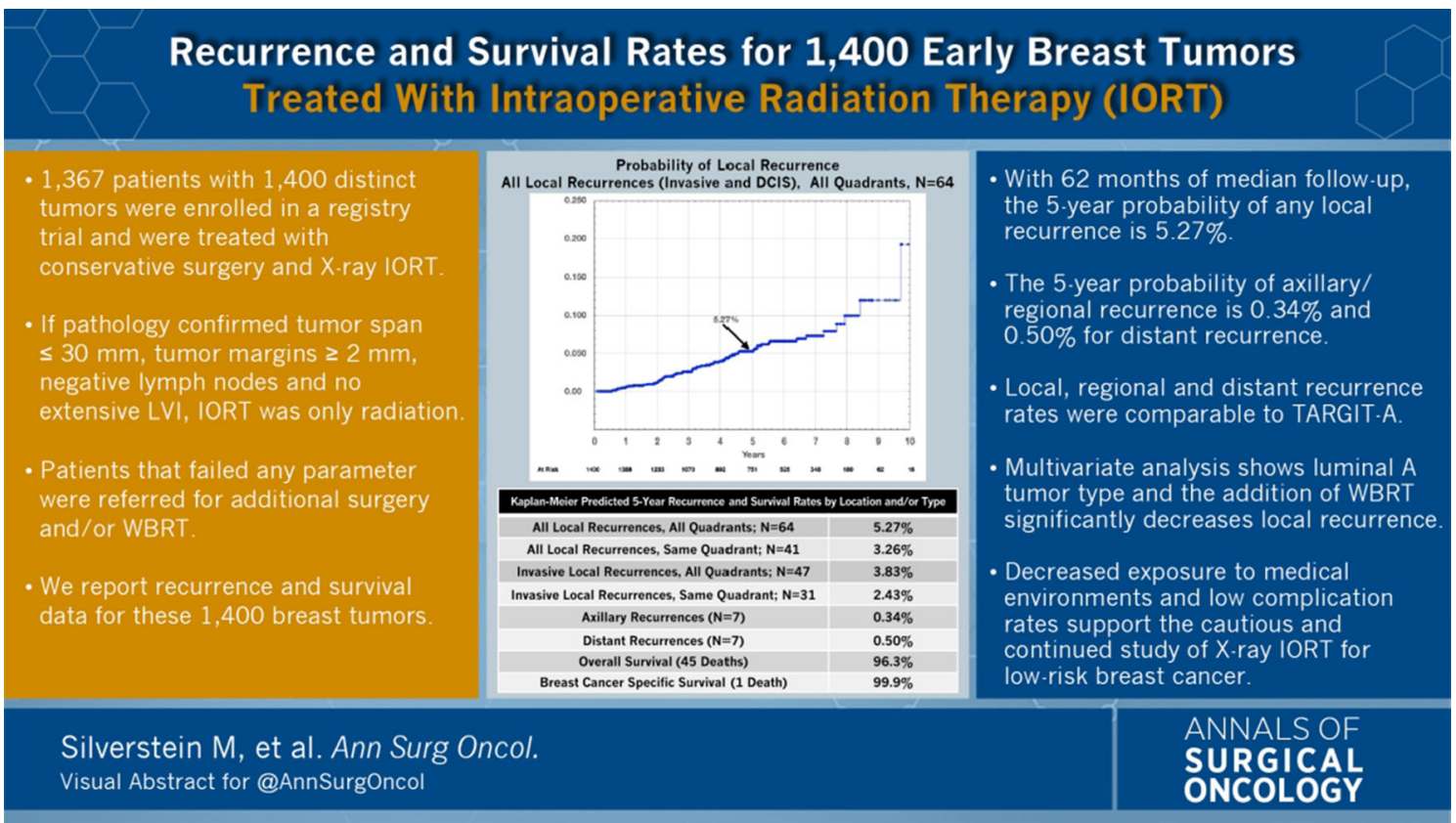

(C) Society of Surgical Oncology 2022

Published Online: 20 February 2022

M. J. Silverstein, MD

e-mail: Melsilver9@gmail.com
DISCLOSURE There are no conflicts of interests.

Publisher's Note Springer Nature remains neutral with regard to jurisdictional claims in published maps and institutional affiliations. 